\title{
EM LIBERDADE: O VIVIDO INVENTADO \\ COMO EXERCÍCIO DE METAFICÇÃO E DE DENÚNCIA DA OPRESSÃO
}

EM LIBERDADE: THE LIVED INVENTED

HOW EXERCISE METAFICTION AND WITHDRAWAL OF OPPRESSION

\author{
Carlos Barbosa Júnior ${ }^{1}$ \\ Naira de Almeida Nascimento ${ }^{2}$
}

\section{Resumo}

Por meio de exame cuidadoso de alguns excertos da obra, este trabalho tem como objetivo a análise do livro Em liberdade de Silviano Santiago, para verificar como o autor estabelece sua leitura da época de Graciliano Ramos retratada no romance. Para cumprir tal objetivo, será utilizado o conceito de metaficção historiográfica e serão postas em questão as características do pós-modernismo estabelecidas por Linda Hutcheon.

Palavras-chave: Graciliano Ramos. Silviano Santiago. Em liberdade. Metaficção historiográfica. Literatura brasileira.

\begin{abstract}
Through detailed examination of the novel's excerpts, this paper aims to analyse Em Liberdade, written by Silviano Santiago, in order to verify how the author establishes his understanding on Graciliano Ramos epoch. To achieve that goal, this paper underlies on the historiographic metafiction concept and brings up postmodernism characteristics, both studied by canadian academic Linda Hutcheon.
\end{abstract}

Keywords: Graciliano Ramos. Silviano Santiago. Em liberdade. Historiographic metafiction. Brazilian literature.

\section{Introdução}

O presente trabalho tem como escopo a análise da obra Em Liberdade: uma ficção de Silviano Santiago. Para cumprir tal objetivo, além da necessária análise do texto de Silviano, serão discutidos os conceitos de metaficção historiográfica e de pósmodernismo, de conformidade com Linda Hutcheon (1991).

Também será colocado em questão como o texto de Silviano Santiago se realiza como ficção histórica e como nele são mobilizados alguns recursos expressivos para a

\footnotetext{
${ }^{1}$ Especialista em Literatura Brasileira e História Nacional pela UTFPR-Curitiba. E-mail: carlos.barbosajunior@gmail.com

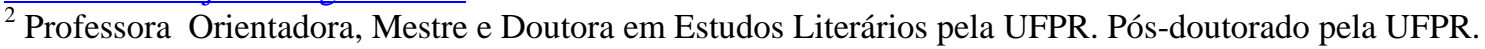
Prof $^{a}$ Adjunto da UTFPR-Curitiba. E-mail: naira.alm@gmail.com
} 
construção narrativa dos eventos históricos, mediante a análise de excertos selecionados de Em liberdade, publicado em 1981.

O leitor, habituado à análise e ao estilo peculiar que caracterizam tanto os volumes de ficção de Graciliano Ramos, bem como os chamados "livros pessoais” do autor, Infância e Memórias do Cárcere (CANDIDO, 2006, p. 69), é levado a acreditar que Em liberdade é realmente o diário escrito por Graciliano após sua libertação. Isso se deve à simulação que Silviano faz do texto, e mesmo do pensamento, de Graciliano.

Destarte, há Em Liberdade uma espécie de espelhamento de Memórias do Cárcere. Além da imitação do estilo de Graciliano e da reconstituição do Rio de Janeiro da década de 30 do século passado, esse espelhamento é construído pela similitude das reflexões que o narrador de Memórias do Cárcere faz sobre a escrita, sobre a representação da realidade e sobre o papel do escritor, como no seguinte trecho:

Certos escritores se desculpam de não terem forjado coisas excelentes por falta de liberdade - talvez ingênuo recurso de justificar inépcia ou preguiça. Liberdade completa ninguém desfruta: começamos oprimidos pela sintaxe e acabamos às voltas com a Delegacia de Ordem Política e Social, mas nos estreitos limites a que nos coagem a gramática e a lei, ainda nos podemos mexer. [...] Não caluniemos o nosso pequenino fascismo tupinambá: se o fizermos, perderemos qualquer vestígio de autoridade, quando formos verazes, ninguém nos dará crédito. De fato ele não nos impediu escrever. Apenas nos suprimiu o desejo de entregar-nos a esse exercício. [...] Quem dormiu no chão deve lembrar-se disto, impor-se disciplina, sentar-se em cadeiras duras, escrever em tábuas estreitas. Escreverá talvez asperezas, mas é delas que a vida é feita: inútil negá-las, contorná-las, envolvê-las em gaze. (RAMOS, 1996, p. 34).

Tal similitude de pensamento e de linguagem dos dois narradores, o de Memórias do Cárcere e o de Em Liberdade, é possível de ser aferida cotejando a citação acima com o seguinte excerto:

Dizem que os meus livros são construídos demais. Existe nesse tipo de frase um elogio implícito à espontaneidade na execução da obra de arte que me incomoda [...]

O leitor de jornal (ou de romance espontâneo) não quer fazer esforço algum quando lê. Contenta-se em absorver a escrita de um outro como se fosse um papel mata-borrão. [...] Este leitor tem uma visão fascista da literatura. Fascismo não é apenas governo autoritário e forte, de preferência militar, que deixa que se reproduzam, sem contestação, as forças econômicas da classe dominante. Fascismo existe todas as vezes em que o ser humano se sente cúmplice e súdito de normas. Amolecem o cérebro, espreguiçam os músculos, soltam a fibra. O homem deixa-se invadir por modelos de 
comportamento que não representam a sua energia, mas que o transformam em um uniforme a mais. Chega a uma triste conclusão: quanto mais semelhante sou ao meu semelhante, mais sei a respeito do mundo, da sociedade e das pessoas.

A verdadeira leitura é uma luta entre subjetividades que afirmam e que não abrem mão do que afirmam, sem as cores da intransigência. O conflito romanesco é, em forma de intriga, uma cópia do conflito da leitura. Ficção só existe quando há conflito, quando forças diferentes digladiam-se no interior do livro e no processo de sua circulação pela sociedade.

Encontrar no romance o que já se espera encontrar, o que já se sabe, é o triste caminho de uma arte fascista, onde até mesmo os meandros e os labirintos da imaginação são programados para que não haja a dissidência de pensamento. (SANTIAGO, 1994, p. 122-123).

Assim, vê-se que desde as primeiras páginas a leitura de Em liberdade, que curiosamente traz no subtítulo a sentença "uma ficção de Silviano Santigo”, causa certa estranheza ao leitor - principalmente àquele familiarizado com a obra de Graciliano Ramos.

Qual a necessidade de se escrever no subtítulo de um livro que se trata de uma ficção? Seria para criar uma oposição aos fatos narrados no pré-texto, na forma de "Nota do Editor" e "Sobre esta edição”? Ou seria apenas para mostrar o aspecto contraditório da ficção presente no texto de "Em Liberdade"? Ou ainda, seria uma estratégia para sinalizar ao leitor de forma sutil que o texto, que se apresenta como um simples diário, na verdade é um romance com um elaborado labirinto narrativo?

Tais "notas do editor” nos dão conta das circunstâncias da existência real dos originais do diário ${ }^{3}$ escrito por Graciliano Ramos, assim que este conquistou sua liberdade, em 13 de janeiro de 1937. Também registram o envio desses originais a Silviano Santiago pela viúva de um amigo de Graciliano, que exercera o papel de fiel depositário do diário: “ensinando na Universidade de Rutgers, Nova Jérsei (Estados Unidos da América) recebi no dia 12 de novembro um estranho pacote vindo do Brasil.” (SANTIAGO, 1996, p.11).

Além do enredo, que reconstitui o quotidiano de um importante escritor brasileiro na década de 30 do século passado, Em Liberdade apresenta reflexões agudas sobre o fazer artístico - o que é uma das características marcantes das obras classificadas como “metaficção historiográfica” (HUTCHEON, 1991, p. 21) - além de

\footnotetext{
${ }^{3}$ A descoberta ou o achado de um "original” por um escritor que o edita é um artifício bastante produtivo na ficção, presente na tradição literária do ocidente há mais de quatro séculos. Foi utilizado por Miguel de Cervantes no "Don Quijote”, por muitos considerado o primeiro romance moderno.
} 
estabelecer reflexões sobre o papel dos intelectuais e dos artistas de um país subdesenvolvido e sujeito ao arbítrio. Conforme observou o professor Antônio Esteves, o questionamento quanto ao papel do intelectual diante do poder político na sociedade brasileira é um dos elementos nucleares da segunda parte do romance (ESTEVES, 2010, p. 119). E como já observado, tais reflexões são muito semelhantes às feitas pelo narrador de Memórias do Cárcere.

Esses e outros questionamentos, como se verá brevemente no presente trabalho, são colocados ao leitor desde os umbrais de Em Liberdade.

\section{A história do personagem}

É inconteste na historiografia brasileira que o escritor Graciliano Ramos foi feito prisioneiro sem acusação formal por forças policiais, em 1936, na cidade de Maceió (ESTEVES, 2010, p. 111). Na época, Graciliano era Diretor de Instrução Pública do Estado de Alagoas (cargo que corresponde atualmente ao de Secretário de Estado da Educação).

Graciliano já havia publicado os romances Caetés (1933) e São Bernardo (1936). De Maceió, o escritor é levado para o Recife e posteriormente para o Rio de Janeiro. Permaneceu preso por dez meses e dez dias no presídio da Ilha Grande e na Casa de Detenção na Rua Frei Caneca. Durante o período da prisão é publicado pela Livraria José Olympio o romance Angústia, que teve boa aceitação por parte da crítica e tornou o autor conhecido. Apenas em 1946 é que Graciliano inicia a fatura de Memórias do Cárcere, que será publicado em 1953, depois da morte do autor.

Na década de 70 do século passado, Silviano Santiago, poeta e ensaísta ${ }^{4}$, parte desses fatos históricos para, conforme consta na epígrafe do livro, “construir o seu Graciliano Ramos”. A publicação deu-se em 1981, durante o período da ditadura militar que teve início com o golpe de estado de 1964.

\section{A leitura do diário de um narrador inventado}

\footnotetext{
${ }^{4}$ Santiago, que fez carreira como professor universitário, publicou antes do lançamento de Em Liberdade o volume de poesias Crescendo Durante a Guerra numa Província Ultramarina e o de ensaios Uma Literatura nos Trópicos.
} 
O início da leitura de Em Liberdade gera certo incômodo, em virtude da contradição entre o que consta no pré-texto e no texto, como já observado. Além disso, a voz narrativa pertence a um personagem que, não obstante ser um conhecido autor da historiografia literária brasileira é, também, um ex-presidiário que carrega fundas cicatrizes do período em que esteve no cárcere; e, mesmo com a saúde fragilizada, possui uma lucidez admirável.

Poucas páginas adiante e o leitor já se perde no labirinto dos detalhes da realidade representada do Rio de Janeiro da década de 30. A convivência de Graciliano com sua mulher Heloísa, escritores e intelectuais; a vida e os costumes sociais, o rádio, o carnaval e o futebol da época estão retratados com minúcia no livro.

Nomes da historiografia literária, de artistas e mesmo políticos da década de 30 do século passado são utilizados como personagens: Graciliano (o narrador), Zé Lins, Manuel Bandeira, Santa Rosa, Drummond, Osvald de Andrade, Gustavo Capanema, Mário de Andrade, entre outros.

A obra foi escrita na década de 70. Admira o fôlego de pesquisador do ficcionista, uma vez que o grau de verossimilhança presente no texto de Em Liberdade é, sem dúvida, lastreado em exaustivas pesquisas feitas sobre o Rio de Janeiro da década de 30 do século passado.

Há no texto preciosismo nos registros de época, que são costumeiramente acompanhados do olhar sempre crítico do intelectual. Como exemplo, transcreve-se o trecho em que o narrador fala dos desfiles do sábado e da terça-feira do carnaval carioca de 1937:

O carnaval, quando crítico e debochado, pode, no máximo, deixar transparecer o desejo de vingança que existe em todo aquele que se considera súdito de alguém. Esse desejo, no entanto, não é construtivo e, por isso, não é verdadeiramente revolucionário. Se o fosse, o Brasil seria um país socialista desde o século passado. A história nos ensina o contrário: terminados os regimes fortes, terminam as críticas feitas pelos blocos e grandes sociedades; fica o carnaval na praça. [...]

O carnaval carioca é o produto que o executivo exporta para o resto do país e para o estrangeiro, para dizer como tudo vai bem sob o calor tropical do verão. Feitas essas ressalvas, posso melhor admirar a crítica da eletrificação da Central do Brasil, feita no domingo pelo bloco Turunas de Monte Alegre. Acusavam eles a prefeitura pelos abusos que vem cometendo nos subúrbios. Em nome do progresso, desapropria casas, deixando os moradores com alguns minguados mil-réis [...] e sem lugar para morar. O progresso, no Brasil, apenas melhora as condições de vida de quem já as têm boas. 
No desfile das Grandes Sociedades, na terça-feira, os Democráticos vieram com uma curiosa crítica aos apartamentos (verdadeiros "apertamentos” como se podia ler na faixa [...]).

Em ambas as alegorias, é o sentido de propriedade que está em jogo. É a velha teoria do liberalismo brasileiro do final do século passado [...].

O mesmo grupo trouxe uma típica alegoria de súdito (ou de "democrata”, se brincarmos com o nome da sociedade): "O grande Domador".

O carro principal leva o título de "Sossega Leão” e nele vê-se um boneco semelhante ao presidente, vestido a caráter, domando um enorme leão, onde se pode ler a palavra “Oposição.” O presidente doma o leão da oposição, e é a esta - e não a ele - que pedem que "sossegue”. Onde está a crítica ao atrevido presidente e a seus comparsas? Em lugar nenhum. O domador é "grande”. Exigem - isso sim - boas maneiras da oposição.

(SANTIAGO, 1994, p.158-160)

Vê-se, destarte, que além do mero registro do que aconteceu no carnaval de rua do Rio de Janeiro, abordando os motivos e temas dos blocos e das "Grandes Sociedades”, o narrador faz uma análise da sociedade brasileira e da política da época.

Depois de uma introdução sobre o sentido pacificador dessa festa popular, à luz da história, o narrador fixa seu olhar na análise das alegorias carnavalescas, tanto do “bloco carnavalesco” (este suburbano, de extração popular), como das “sociedades”, que contemplam o imaginário da classe média e da elite econômica e política do período.

Em ambas as alegorias carnavalescas, a visada crítica do narrador enxerga manifestações do direito de propriedade, conforme o velho liberalismo brasileiro finissecular do XIX. O que dá ensejo ao seguinte questionamento: se nem no carnaval, espaço privilegiado para a crítica bem humorada, a paródia e o deboche, há reprovação quanto ao comportamento do presidente da república e de seu governo inconstitucional e arbitrário, é por que a sociedade tolera, aceita e mesmo concorda com as arbitrariedades, e apenas pede, ludicamente, que a oposição ao governo desse "grande homem” sossegue.

Como visto, o narrador de Em Liberdade afirma a utilidade do carnaval carioca, que é a de ser o produto necessário para as autoridades da capital da República mostrarem para o resto do País e para o exterior que "tudo vai bem sob o calor tropical do verão”.

Destarte, há nesse ponto da narrativa a inserção de um contexto histórico. Sabese que a verossimilhança é um dos mais importantes traços da ficção, cuja importância já foi assinalada por Aristóteles em sua Poética. No excerto em tela, Silviano Santiago 
apresenta o passado com uma profusão de detalhes (o que faz o leitor ter a impressão de que o narrador realmente assistiu ao desfile). Assim, a finalidade de reapresentar o tempo passado na literatura pós-moderna tem o objetivo de revelá-lo com verossimilhança ao presente, como se verá adiante. Porém, tal evocação não parece ser conclusiva ou teleológica, o que constitui, também, uma das marcas da ficção pósmoderna (HUTCHEON, 1991, p. 147).

\section{Tempo e espaço da matéria narrada}

Não há inversões temporais no texto de Em Liberdade. Trata-se, como já observado, de um diário, ou seja, de uma forma de “escrita do eu” muito produtiva na literatura, pelos menos nos dois últimos séculos. Tal característica é uma das marcas na estrutura do texto de Em Liberdade (ESTEVES, 2010, p.113). Assim, o livro descreve fatos ocorridos no período de 14 de janeiro a 26 de março de 1937, dividindo-os em duas partes, correspondentes a dois espaços narrativos.

O primeiro é o do Largo dos Leões (Rua Alfredo Chaves, residência do romancista José Lins do Rego). Nessa casa é que o personagem narrador inicia a escrita do diário, nos períodos em que a personagem Heloísa não está presente. O narrador, ou melhor, o personagem que empresta a voz ao narrador, declara que sua mulher não sabe da existência do diário. Há um período em que Heloísa viaja de navio para o nordeste e Graciliano fica sozinho no Rio de Janeiro.

Já o segundo espaço narrativo é o da Pensão de Dona Elvira (Rua Correa Dutra, Catete). É para este endereço que Graciliano muda-se, sozinho, em 15 de fevereiro de 1937. É no período em que mora na pensão que Graciliano faz uma viagem para São Paulo, acompanhando José Lins do Rego. Em São Paulo, Graciliano tem um sonho com a inconfidência mineira. No sonho, ele é o poeta Claudio Manoel da Costa.

Assim, no momento da narrativa em que há recuo no tempo, o narrador utiliza-se da dimensão onírica, relatando seu sonho para que seja mantida a coerência temporal do texto escrito na forma de diário. Com isso, o autor reafirma o espelhamento entre o narrador inventado de Em Liberdade e o narrador de Memórias do Cárcere.

Com relação à divisão dual dos espaços da narrativa, é possível afirmar que o personagem narrador de Em Liberdade no primeiro espaço narrativo (Largo dos Leões) tinha sua liberdade de expressão como autor e intelectual tutelada pela autoridade de 
outro escritor, o personagem José Lins do Rego - cuja figura proeminente sombreava o personagem Graciliano Ramos. Já no segundo espaço da narrativa, o personagem está sozinho, em liberdade para caminhar com suas próprias pernas, inclusive concebendo projetos de ficção sem o conhecimento nem a concordância de José Lins do Rego.

Dada a notícia esquemática a respeito do que trata o texto ora em debate, do tipo de narrador e de como nele é trabalhada a dimensão temporal, passa-se à análise dos conceitos teóricos aludidos anteriormente.

\section{Pós-modernismo, romance, metaficção e evocação do passado}

O estudo do romance enquanto gênero caracteriza-se por dificuldades particulares. Elas são condicionadas pela singularidade do próprio objeto: o romance é o único gênero por se constituir, e ainda inacabado. As forças criadoras dos gêneros agem sob os nossos olhos: o nascimento e a formação do gênero romanesco realizam-se sob a plena luz da História. A ossatura do romance está longe de ser consolidada, e não podemos ainda prever todas as suas possibilidades. (BAKHTIN, 1993, p. 397).

Tendo em vista o caráter inacabado do gênero romance, um conceito aberto, conforme Bakhtin, e a advertência da Professora Marilene Weinhardt (1998), no sentido de que "Rótulos e nomenclaturas podem servir como estratégias metodológicas, mas devem ser descartados quando produzem limitações”, nesta seção examinar-se-á o conceito de “metaficção historiográfica” proposto por Linda Hutcheon.

Antes, porém, é necessário colocar em questão o conceito de “pós-modernismo”.

Furtando-se a estabelecer uma definição estável e acabada do termo "pósmodernismo”, Linda Hutcheon ${ }^{5}$ registra que tal conceito não é sinônimo de contemporâneo, e prefere situá-lo como relativo à atividade ou processo cultural, elencando algumas de suas características: “aquilo que quero chamar de pósmodernismo é fundamentalmente contraditório, deliberadamente histórico e inevitavelmente político.” (HUTCHEON, 1991, p.32).

Quanto ao caráter histórico do pós-modernismo, Hutcheon assevera que não se trata de um retorno nostálgico ao passado, como acontecia com os romances do século XIX, mas de uma reelaboração crítica.

\footnotetext{
${ }^{5}$ Em vez disso, a autora afirma a necessidade de definir uma "poética” do pós-modernismo, ou seja: “uma estrutura teórica aberta, em constante mutação, com a qual possamos organizar nosso conhecimento cultural e nossos procedimentos críticos.” (p. 32).
} 
Sob esse aspecto, a evocação do passado feita por Silviano na obra Em Liberdade possibilita uma reflexão sobre a situação vivida no Brasil da década de 30 do século passado - o tempo da narrativa. Mas, além disso, tal evocação também faz uma leitura crítica do tempo presente, aquele em que foi escrito Em Liberdade - ou seja, a década de 70 do século passado, período em que o Brasil também era governado por uma ditadura arbitrária e violenta. Silviano consegue tal intento por meio de um episódio do diário, já aludido no presente trabalho, em que o narrador descreve um sonho de Graciliano. No sonho, o narrador-personagem é o poeta Claudio Manoel da Costa.

Sabe-se que o poeta inconfidente foi preso e morreu misteriosamente enforcado no cárcere, antes da chegada em Minas das autoridades da Corte responsáveis pela devassa (o inquérito para a apuração dos responsáveis pela insurreição). Depois do sonho, o personagem Graciliano resolve escrever sobre a Inconfidência Mineira. Passa a frequentar a Biblioteca Nacional com o intuito de fazer pesquisas, como se vê na entrada do diário referente ao dia 5 de março:

Só tenho uma certeza até agora: não quero que o conto incorpore os conhecidos valores estilísticos do historiador, que são a objetividade e a frieza. Em outras palavras: não quero escrever "a” biografia de Cláudio Manoel da Costa. Usarei da linguagem da ficção: será mais uma personagem do que personalidade histórica.

Busco informações precisas, consulto documentos da época, tomo notas e mais notas. Tudo isso deve servir apenas de pano de fundo, de cenário, para o trabalho da minha imaginação. [...] O sonho indicou-me um caminho fértil para o beco sem saída criativo em que me encontrava, e deume a chave para a técnica narrativa que devo usar. Tem de haver uma identificação minha com Cláudio, espécie de empatia, que me possibilite escrever a sua vida como se fosse a minha, escrever a minha vida como se fosse a sua. (SANTIAGO, 1994, p.226).

Vê-se no trecho em exame que o narrador também assinala as diferenças entre a escrita da história e a da ficção, bem como faz referência ao papel dos intelectuais numa sociedade sujeita ao arbítrio. Além disso, também pretende realizar um “espelhamento”, ou seja, escrever sobre a vida do poeta Cláudio como se fosse a dele, Graciliano ${ }^{6}$.

Durante sua pesquisa, o personagem Graciliano descobre que houve uma prestigiada missa em homenagem a Cláudio Manoel da Costa, conforme registra a entrada do diário referente ao dia 15 de março:

\footnotetext{
${ }^{6}$ E nesse jogo de espelhos também está Silviano, como se fosse Graciliano.
} 
Missa é rezada, na Matriz do Pilar, pela alma de Cláudio. Os habitantes da cidade compareceram em massa. Para todos os efeitos, o finado Cláudio Manoel da Costa não atentou contra a sua própria existência. É a Igreja que o diz. A cúria de Vila Rica, zelosa da sua tradição católica romana, não teria ido contra os princípios expressos por santo Tomás de Aquino, na Suma Teologica. O filósofo católico afirma que, antes de tudo, o suicídio atenta contra a Lei Divina. (SANTIAGO, 1994, p.245).

O narrador Graciliano conclui que Cláudio Manoel da Costa não se suicidou, foi assassinado na prisão, pois a missa não teria sido realizada se o falecido fosse suicida.

Neste ponto, Silviano consegue o prodígio de enfeixar não duas, mas três dimensões temporais por meio da apropriação de dois planos temporais da história brasileira em seu texto ficcional.

Em outubro 1975, alguns anos antes da publicação de Em Liberdade, a sociedade brasileira foi surpreendida pela notícia de um crime bárbaro, cometido por integrantes dos chamados “órgãos de segurança”. Mediante convocação para prestar depoimento sobre suas ligações com o Partido Comunista Brasileiro, o conhecido jornalista Vladimir Herzog compareceu no dia 25 à sede do DOI-CODI de São Paulo (Destacamento de Operações de Informações - Centro de Operações de Defesa Interna, órgão ligado ao Exército Brasileiro).

Assim que se apresentou, Herzog foi preso sem acusação formal ${ }^{7}$. No mesmo dia, foi encontrado morto em sua cela. Segundo as autoridades, Herzog suicidara-se por enforcamento. A tese do suicídio não foi aceita pela comunidade israelita de São Paulo. Os judeus responsáveis pela Taharah ${ }^{8}$, ao prepararem o corpo do jornalista para o sepultamento, viram as marcas de tortura e procuraram D. Paulo Evaristo Arns - então arcebispo de São Paulo - que corajosamente foi a público denunciar o crime e ofereceu a catedral da Sé para a realização da missa ecumênica em homenagem ao jornalista.

Assim, Silviano, ao evocar o falso suicídio de 1789, denuncia as arbitrariedades cometidas em outro período, aquele em que foi escrito Em Liberdade.

Linda Hutcheon, partindo das características atribuídas ao pós-modernismo, define "metaficção historiográfica" como sendo um tipo de ficção presente naqueles

\footnotetext{
${ }^{7}$ Como o fora Graciliano Ramos, quarenta anos antes.

${ }^{8}$ Cerimônia em que é lavado o corpo e são realizadas preces de purificação para o sepultamento, conforme a tradição judaica.
} 
"romances populares que, ao mesmo tempo, são intensamente autorreflexivos, e mesmo assim, de maneira paradoxal, também se apropriam de acontecimentos e personagens históricos.” (HUTCHEON, 1991, p. 21).

Verificada a apropriação que Em Liberdade faz do passado, ou seja, de acontecimentos e personagens da história, passa-se à investigação da ocorrência do caráter autorreflexivo do texto (ou seja, a metaficção). Serão examinados, para tanto, alguns excertos da obra de Silviano Santiago:

\begin{abstract}
Abandonar a ficção e adentrar-me pelo diário íntimo, deixando que o livro não seja construído pelo argumento ou pela psicologia dos personagens, mas pelos próprios caminhos imprevisíveis de uma vida vivida. (SANTIAGO, 1994, p. 22).
\end{abstract}

Neste passo, o narrador-personagem faz uma opção em relação ao gênero discursivo de sua escrita. Ou seja, um diário que será composto pela imprevisibilidade de uma “vida vivida”. É negada, assim, a construção de um argumento ou a problematização de personagens, importando-lhe tão somente a escrita do percurso que será cumprido por Graciliano em liberdade.

Ainda na primeira parte do livro, em que a escritura do diário é feita na solidão do quarto de hóspedes da residência do escritor José Lins do Rego, há uma série de questionamentos do narrador em relação às possibilidades e limites da escrita:

Existe alguma lógica na escolha dos sucessivos assuntos de que trato neste diário? Possuo eu esta lógica? Ou seja: sou eu quem organiza os temas? Ou ela está sendo dada de presente, como eu acreditei, pelo acaso? No início deste, dei mais crença à força e ao papel das circunstâncias do que eles merecem. Dou-me conta de que não posso escrever neste bloco tudo o que acontece, mesmo se qualifico o que acontece de importante. Pois o que é importante e o que não o é, quando não se tem uma perspectiva de avaliação? (SANTIAGO, 1994, pg. 132-133).

O escritor parece colocar em questão o seu próprio ofício: é possível aferir o que é o que não é importante para depois representá-lo por meio da escrita? Qual o critério para a escolha dos assuntos narrados? 
Estes questionamentos dão oportunidade para que o leitor faça a sua parte, tenha um papel ativo, qual seja, o de conhecer os bastidores da escrita e adentrar no universo da matéria narrada, como quer o escritor narrador. ${ }^{9}$

Além de diferenciar criticamente as duas formas narrativas, o diário e o romance, e convidar o leitor a fazer parte da reflexão sobre o fazer artístico, o trecho também serve como espécie de engodo a um leitor desavisado, pois reafirma que o texto não é uma ficção, mas um diário escrito pelo próprio Graciliano Ramos.

Tal estratégia discursiva também serviria para justificar algumas fraturas e contradições do texto ficcional, como, por exemplo, a que ocorre no trecho em que há um diálogo entre o hóspede, personagem que narra, e o escritor José Lins do Rego. Tal diálogo revela diferenças de concepção de literatura, e mesmo do papel que cabe ao escritor:

\footnotetext{
Aproximo-me de Zé Lins, que foi levar ao portão a última leva de romeiros. Volta satisfeito e feliz. Nossos rostos, em confronto, serviriam de modelo para as duas máscaras do teatro: a da comédia e a da tragédia. [...] Diante do espírito festivo e jovial de Zé Lins, não sabia o que dizer. Disse qualquer coisa como missão cumprida, agora encontrar um novo modo de vida. [...]

Vi o sorriso de Zé Lins e encabulei-me. Era um sorriso discreto, desses que apenas despontam nos lábios, convincentes como uma flor de retórica, pois não chegam a constituir som. Zé Lins foi aproximando-se de mim, agora abanando a cabeça, como se conversasse com um menino deveras traquinas, e deu-me uns tapinhas nas costas. Em seguida, ainda em silêncio, passou o braço direito nas minhas costas. O sorriso abriu-se brilhante como em cara de ator consumado:

- Quando você vai aprender, Graça?

- Nunca, pelo visto.

Ficamos em silêncio por algum tempo. Tive tempo de tirar um cigarro do maço e acendê-lo, enquanto ele bebia um gole de aguardente (...)

(SANTIAGO, 1994, p. 67-68).
}

“A última leva de romeiros” diz respeito aos visitantes que compareceram na residência de Zé Lins para ver Graciliano, que, tímido, não se sentiu nem um pouco à vontade com o assédio de desconhecidos e com as perguntas que faziam sobre o período

\footnotetext{
${ }^{9}$ E, também, como quer Silviano Santiago, pois o autor defende que todo escritor é antes de tudo, leitor: "A literatura é um discurso mentiroso, inventado, fabulado, mas isso não quer dizer que seja falso. É inegável que a literatura tem uma função, assim como todas as artes têm. O primeiro cuidado a ser tomado, se a gente fala de função de literatura, é não fazer uma divisão entre produtor e consumidor. Ou seja, não fazer distinção entre escritor e leitor. Acho que a literatura tem a mesma função para ambos. Não existe um escritor que não seja leitor”.

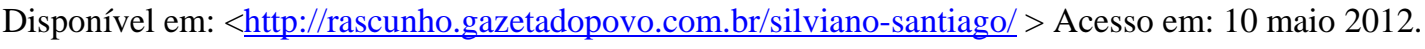


do cárcere. Graciliano não aceitava o papel de vítima. Queria seguir em frente, mas sentia que era tolhido e puxado para o passado.

Uma das fraturas do texto ficcional ora em estudo, que pode ser justificada pelo caráter de diário do texto, como afirmou o narrador, dá-se na composição do espaço narrativo.

Onde estão os protagonistas? No portão da casa do escritor, diz o texto. Sem mais, aparecem dentro da sala da residência, talvez, e o que é mais estranho, Zé Lins toma um gole de aguardente! Onde fora servida a bebida? Não há referência no texto ao espaço da ação nele representada.

Tal contradição na construção do espaço narrativo não é gratuita. Parece querer reafirmar o caráter de diário do texto ficcional para o leitor, pois o personagem narrador afirma:

\begin{abstract}
Não caio na armadilha da fiç̧ão. Tendo descoberto uma contradição na arquitetura do diário, não vou de repente reescrever tudo com o fim de salientar a clareza de propósitos do livro que disto sairá. Não, não devo reescrever. Faria do diário um romance. É preciso que ele traduza os descaminhos do romancista e as perplexidades da escrita. É por esses dois importantíssimos dados que o diário se diferencia da ficção. A presença onipotente do romancista, construtor de enredo, é relegada a segundo plano. A sequência das cenas é dada pelos caminhos e descaminhos de uma vida. Sigo os passos do personagem, não sigo o enredo do romancista. Pela primeira vez. (SANTIAGO, 1991, p. 134. negritou-se)
\end{abstract}

Mais adiante, na segunda parte do livro, em que o espaço da narrativa é a Pensão de D. Elvira, no Catete, motivado a pesquisar dados sobre a inconfidência mineira, há a seguinte reflexão do personagem Graciliano sobre a verdade e a escrita da história:

A verdade histórica - sendo obediente à seta da cronologia e circunscrita às determinações locais de caráter sócio-econômico - congela as partes fragmentadas na sua particularidade, impossibilitando que se tenha uma compreensão global dos acontecimentos. (SANTIAGO, 1994, p. 226).

O narrador parece buscar em sua escrita da história a verossimilhança, pois a mesma possibilitaria a “compreensão global dos acontecimentos”, o que não seria possível alcançar com a mera obediência à cronologia e às determinações de caráter sócio-econômico. 
Hutcheon afirma que antes do advento da chamada "história científica" no século XIX, não havia uma distinção nítida entre a escrita da literatura e a da história. A partir de então, processou-se uma divisão, com o surgimento de duas disciplinas distintas. Porém, a autora relativiza tal cisma a partir do advento do pós-modernismo:

\footnotetext{
Entretanto, é essa mesma divisão entre o literário e o histórico que hoje se contesta na teoria e na arte pós-modernas, e as recentes leituras críticas da história e da ficção têm se concentrado mais naquilo que as duas formas de escrita têm em comum do que em suas diferenças. Considera-se que as duas obtêm suas forças a partir da verossimilhança, mais do que a partir de qualquer verdade objetiva; as duas são identificadas como construtos linguísticos, altamente convencionalizadas em suas formas narrativas e nada transparentes em termos de linguagem ou de estrutura; e parecem ser igualmente intertextuais, desenvolvendo os textos do passado com sua própria textualidade complexa. (HUTCHEON, 1991, p. 141, negritou-se).
}

Assim, não há apenas questionamentos quanto ao fazer artístico que envolve a escrita da ficção no livro Em liberdade. O trecho acima transcrito revela que também há no texto questionamentos a respeito da escritura da história - o que denota o questionamento das fronteiras entre a escrita da história e da ficção na obra em exame, que coloca em relevo a questão da verossimilhança para a legitimidade de ambas as modalidades discursivas.

\section{Considerações finais}

Pelos excertos examinados, depreende-se que Em liberdade: uma Ficção de Silviano Santiago pode ser classificada como “metaficção historiográfica”, uma vez que se encontram presentes na obra a utilização de personagens e de acontecimentos históricos (apropriação do passado) e o questionamento do fazer artístico com considerações sobre os bastidores da criação literária, ou seja, a metaficção. Inclusive a respeito da escrita da história.

O único reparo a ser feito em relação ao conceito de "metaficção historiográfica" estabelecido por Linda Hutcheon em relação ao texto de Em Liberdade diz respeito às características da cultura brasileira e do estágio de desenvolvimento de nosso leitorado, à época da publicação do romance. Por mais que seja conhecido atualmente, 
principalmente pelo público universitário dos cursos de letras, não se pode afirmar que Em liberdade seja um "romance famoso e popular", conforme o conceito estabelecido por Hutcheon para metaficção historiográfica ${ }^{10}$. Como a obra teve até o momento apenas quatro edições, a última delas em 1994, não parece plausível considerá-la um "romance popular".

\section{Referências}

BAKHTIN, Mikhail. Questões de literatura e de estética: a teoria do romance. $3^{\mathrm{a}}$. ed. São Paulo: Editora da UNESP/Hucitec, 1993.

CANDIDO, Antonio. Ficção e Confissão: ensaios sobre Graciliano Ramos. $3^{\mathrm{a}}$. ed. Rio de Janeiro: Ouro sobre azul, 2006.

ESTEVES, A. R. O romance histórico brasileiro contemporâneo (1975-2000). São Paulo: Editora UNESP, 2010.

HUTCHEON, Linda. Poética do pós-modernismo: história, teoria e ficção. Rio de Janeiro: Imago, 1991.

RAMOS, Graciliano. Memórias do cárcere. Rio de Janeiro: Record/Altaya, 1996.

SANTIAGO, Silviano. Em liberdade: uma ficção de Silviano Santiago. 4a . ed. Rio de Janeiro: Rocco,1994.

WEINHARDT, Marilene. Quando a história vira ficção. In: ANTELO, Raul et al. Declínio da arte, ascensão da cultura. Florianópolis: Letras Contemporâneas, 1998.

\footnotetext{
10 “[...] romances populares que, ao mesmo tempo, são intensamente autorreflexivos, e mesmo assim, de maneira paradoxal, também se apropriam de acontecimentos e personagens históricos” (1991, p. 21).
} 